\title{
CVX Theory in CCCCCCVX Languages: Implications for Universal Grammar
}

\author{
Michael Marlo \\ University of Michigan
}

\begin{abstract}
This article provides a critical review of Duanmu's (2002) proposal that there is a universal CVX syllable structure, having a singleconsonant onset position (C) and a rhyme (VX) that consists of two positions: one for a vowel (V) and one for either a second vowel or a consonant $(\mathrm{X})$. Duanmu reanalyzes possible and impossible consonant clusters in onset position of English and Chinese in terms of what can fit into the single $\mathrm{C}$ slot, given the restrictions on what constitutes a segment in articulator-based feature theory, rather than in terms of sonority, as in "classic" analyses (e.g., Kenstowicz 1994). The predictions of Duanmu's CVX theory are evaluated here in light of data from three languages that superficially, at least, pose the greatest challenges to a theory that predicts a universally simple syllable structure: Spokane Salish, Bella Coola, and Sipakapense Maya-languages that have been reported to allow long sequences of consonants in onset position. Careful evaluation of the data
\end{abstract}

\footnotetext{
* I would like to thank Rusty Barrett, San Duanmu, Robert Felty, Sally Thomason, and three anonymous reviewers for comments. Any errors or misunderstandings are my own.
} 
76 CVX Theory in CCCCCCVX Languages: Implications for Universal Grammar

reveals that the languages indeed appear to have simple syllable structure, as claimed in Duanmu's theory, although slightly different turn from the predictions of the CVX theory. Given these results, implications for phonological universals and the role of sonority, prosodic licensing, and stray erasure in phonological theory are considered.

Keywords: phonology, syllable structure, universals

\section{Introduction}

One of the major goals in generative linguistics is to identify universal principles and structures common to all languages. In the field of phonology, with only a handful of exceptions (e.g., Steriade 1999), it is generally accepted that all languages have at least some kind of syllable structure. However, whether there is a single syllable structure that all languages share is a topic of much debate. Duanmu (2002) makes a strong claim that there is a universal CVX syllable structure, which permits exactly three segment slots. The CVX structure is composed of a single-consonant onset slot (C), and a rhyme (VX) with two slots for a vowel (V) and either a second vowel or a consonant (X), as in (1). ${ }^{1}$

(1) CVX syllable structure

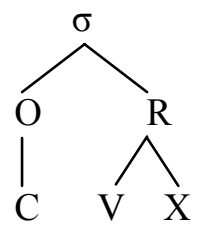

While Duanmu (2002) provides evidence that this structure can

\footnotetext{
${ }^{1}$ Long vowels take two slots, $\mathrm{V}$ and $\mathrm{X}$.
} 
be used to account for Chinese and English, it is unclear if CVX alone is sufficient to represent languages that have been reported to have more complex syllable structures. In this article, I consider the CVX proposal against other theories of syllable structure in light of data from Spokane Salish (Bates \& Carlson 1992), Bella Coola (Bagemihl 1991), and Sipakapense Maya (Barrett 1999, 2000). Spokane Salish and Sipakapense Maya are quite unlike English and Chinese in that they allow long strings of initial and final consonants. For lack of space, I restrict the discussion to onset clusters in these languages. In Section 0, I outline the relevant aspects of the CVX theory. In Sections 0-0, I discuss the three case studies of syllable structure in Spokane Salish, Bella Coola, and Sipakapense Maya, respectively. In Section 6, I consider the role of sonority, prosodic licensing, and stray erasure in phonological theory, issues that are implicitly raised by the data and analyses presented in the earlier sections of the article. Finally, I make concluding remarks in Section 0 .

\section{CVX Theory}

Classic approaches to possible and impossible consonant clusters in English have made reference to the sonority hierarchy, given in (2), and the degree to which the consonants in the cluster must different in sonority (Kenstowicz 1994, Roca \& Johnson 1999, and references therein). In these analyses of English clusters, there are four degrees of sonority, and onset clusters must rise in sonority from the first to the second consonant by at least two degrees in the hierarchy. This restriction is called the 'minimal sonority distance' (MSD). 
(2) Sonority Scale in English

Sounds

Glides

Liquids

Nasals

Obstruents

\section{Sonority Value}

4

3

2

An analysis of possible and impossible Chinese onset clusters can make use of the same technology, with some modifications. The only possible onset clusters in Chinese are consonant-glide sequences. In order to account for this fact using sonority alone, the same sonority scale and MSD as English cannot be maintained. As illustrated in (3), all distinctions among consonants are collapsed (vowels $>>$ glides $>>$ consonants) in the Chinese sonority scale, and the MSD for permissible clusters is 1 (c.f., 2 in English).

(3) Sonority Scale in Chinese

$\underline{\text { Sounds }}$

Glides

\{Liquids, Nasals, Obstruents\}

\section{$\underline{\text { Sonority Value }}$}

2

1

Duanmu levies several criticisms against the sonority-based analyses of possible and impossible consonant sequences. In English, some clusters, such as [tl] and [fw], satisfy the minimal sonority distance of 2 in English, but they are not attested in the inventory. Other clusters, such as [st] and [sn], violate the MSD but are found in the inventory. These inconsistencies require the addition of two additional assumptions to the sonority-based analysis, namely, i) the two sounds of a cluster must not have the same place of articulation and ii) initial [s] and [S] may be added. However, even with additional assumptions, some clusters that violate the MSD and the constraint against adjacent homorganic segments in a cluster are still present in the inventory $([\mathrm{lj}, \mathrm{rw}, \mathrm{tr}, \mathrm{dr}])$, and some cluster 
combinations that seem to meet all the requirements are not present ([nw, zr, 3w, 3,r 31, ðw, ðr, ðl, $\theta 1]$ ).

Duanmu also criticizes the sonority analysis of Chinese clusters. While this analysis allows for a description of possible and impossible onset clusters in Chinese, it is a less general theory because the sonority scale is not identical to that of English and the MSD is a different value. Further, it does not explain why Chinese is less sensitive to sonority differences among consonants than English and why, for example, the MSD for [lw] is large enough for Chinese but not for English.

Duanmu (2002) reanalyzes initial consonant clusters (e.g., [pl, pr]) and consonant-glide clusters (e.g., [kw, pj]) in English and Chinese as single complex segments, rather than as a sequence of two sounds governed by sonority. Duanmu argues that the singleslot analysis accounts for the permissible and impermissible sounds at least as well as an analysis that relies on a sonority hierarchy, maintaining a simpler structure and having fewer additional assumptions.

\subsection{Articulator-based Feature Theory}

The feature geometry assumed by Duanmu (2002) is given in (2) (c.f., Clements (1985), Sagey (1986), Ladefoged \& Halle (1988), McCarthy (1988), Steriade (1989), Kenstowicz (1994) and Halle (1995)). This feature geometry is based on articulator-based feature theory, which defines what a possible single sound is. Articulatorbased feature theory distinguishes features and articulators. Articulators are the movable parts in the vocal tract that participate in speech production, and the gestures made by the articulators constitute the features. 
(4) Articulator-based Feature Geometry

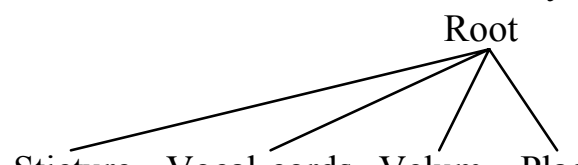

Sticture Vocal-cords Velum Place
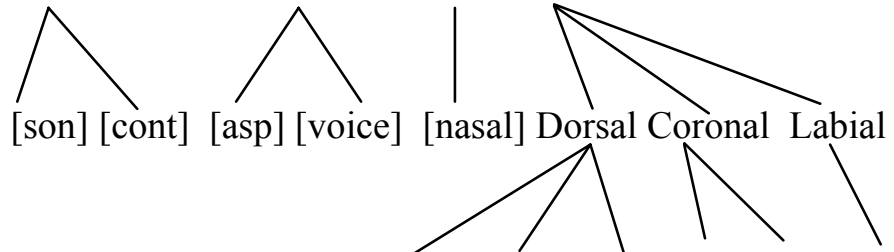

[high] [low] [back] [ant] [lat] [round]

The primary criterion that determines what a single segment can be is the No Contour Principle, given in (5), which states that a single root node can at most have one specification for a given feature/articulator (Duanmu 1994). Although a sound may use several articulators and features at once (e.g., [ $\left.\mathrm{tcc}^{\mathrm{w}}\right]$ ), a single sound cannot be characterized simultaneously by both [+round] and [round], for example, or both [+nasal] and [-nasal]. When a complex segment is characterized by multiple articulators, the articulator with the greater degree of stricture is considered the major articulator (represented throughout by * after the major articulator, following Kenstowicz (1994)). The closure of the minor articulator is left unspecified, although it is always assumed to be that of an approximant, i.e., [+son, -cont].

(5) No Contour Principle (for a Single Segment)

$\begin{array}{ll}* \mathrm{~N} & \mathrm{~N}=\text { any node } \\ {[\alpha \mathrm{F}][-\alpha \mathrm{F}]} & \mathrm{F}=\text { any value }(\text { i.e. },+ \text { or }- \text { ) }\end{array}$




\subsection{Single-slot Analysis of Chinese}

The single-slot analysis argues that what appear to be twoconsonant clusters in English and Chinese onsets can be represented as single complex segments. The Chinese case is somewhat simpler, since, as stated above, the only onset clusters found in Chinese are consonant-glide sequences, which can all be represented as single sounds. Chinese has three glides: [j, w, u]. Examples are given in (6).

(6) Sounds Examples

$\begin{array}{llll}{[\mathrm{t}]} & \text { ta } & \text { 'he' } & \text { Coronal* } \\ {[\mathrm{k}]} & \text { kan 'see' } & \text { Dorsal* } \\ {\left[\mathrm{t}^{\mathrm{W}}\right]} & \text { tuan } & \text { 'league' } & \text { Coronal*, Labial } \\ {\left[\mathrm{t}^{\mathrm{t}}\right]} & \text { tian } & \text { 'sky' } & \text { Coronal*, Dorsal-[-back] } \\ {\left[\mathrm{l}^{\mathrm{H}}\right]} & \text { lue } & \text { 'abbreviate' } & \text { Coronal*, Labial, Dorsal-[-back] }\end{array}$

\subsection{Single-slot Analysis of English}

Duanmu (2002) also shows how the single-slot analysis can handle the 56 possible two-sound clusters in English onsets, given in (7). ${ }^{2}$ The difference between the simple and complex labial stops [p] and [pw] is that [pw] is not only specified Labial, it also has [+round]. The lateral liquid [1] is Coronal; the retroflex liquid [rw] $\left({ }^{\prime} \mathrm{r}^{3}\right.$ ) is Coronal and Labial. The glide [j] is Dorsal-[-back] and Coronal. Therefore the approximant complex articulations can all be distinguished in terms of features and minor articulations, as shown by the examples in (8), which compare the articulator representations of the set of voiceless velar stops.

\footnotetext{
${ }^{2}$ See Duanmu (2002) for examples of each of these clusters.

${ }^{3}$ Because English ' $r$ ' is produced with rounding of the lips, Duanmu represents the segment as [rw], with a secondary Labial articulation.
} 
(7) English Onset Clusters

pw, pr, pl, pj, tw, tr, tj, kw, kr, kl, kj, bw, br, bl, bj, dw, d r, dj, gw, gr, gl, gj, fw, fr, fl, fj, $\theta w, \theta r, \theta j, s w, s r, s l, s j, s$ $\mathrm{p}, \mathrm{st}, \mathrm{sk}, \mathrm{sf}, \mathrm{sv}, \mathrm{sm}, \mathrm{sn}, \int \mathrm{w}, \int \mathrm{r}, \int \mathrm{t}, \int \mathrm{n}, \int \mathrm{m}, \mathrm{vw}, \mathrm{vr}, \mathrm{vl}, \mathrm{vj}, \mathrm{zw}$, zl, zj, hj, lj, nj, mj

(8) $\underline{\text { Sounds }}$ Examples $\quad$ Articulator Representation [k] car Dorsal* [kw] quick Dorsal*, Labial

[kl] class Dorsal*, Coronal-[+lateral]

[kj] cute Dorsal*-[-back], Coronal

[krw] cry Dorsal*, Coronal-[-anterior], Labial

The single-slot analysis also predicts that certain sequences of sounds cannot be represented as single sounds (i.e., those that violate the No Contour Principle). For example, the sounds in (9), cannot be represented as a single segment.

(9) Sounds Problems

[tm] [t] is [-nasal]; [m] is [+nasal].

[bz] [b] is the major articulator; $[\mathrm{z}]$ cannot be a major or minor articulator. ${ }^{4}$

The single-slot analysis also seems to predict that certain sequences that are found in English, such as those in (10), should not be attested because they cannot be represented as a single segment. This same problem is even more obvious for three-sound clusters in English such as [spr, skr], which also cannot be represented as a single segment. The CVX theory does not try to

\footnotetext{
${ }^{4}$ [z] cannot be a major articulator because its stricture [-son, + cont] is different from that of [b] [-son, -cont]. [z] cannot be a minor articulator, either, because its stricture is not that of an approximant [+son, -cont].
} 
force these initial extra segments into the same syllable by making special concessions for them; they are simply not part of the onset, not part of the syllable. Prosodic licensing (i.e., Ito (1986)) is not a genuine requirement in the CVX theory. While segments that can be syllabified should be part of the syllable (i.e., there is a preference for prosodic licensing), other factors can force segments (often on the periphery) to be unsyllabified.

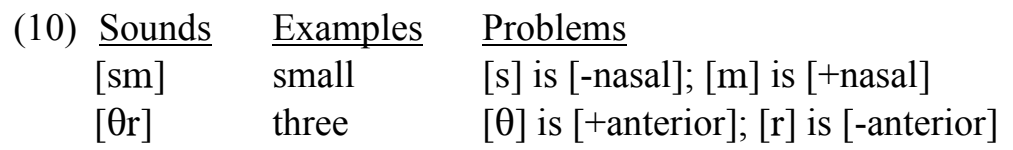

The class of segments in English that are tolerated outside the syllable is restricted to the coronal fricatives $\left[\mathrm{s}, \int, \theta, \mathrm{z}\right] .^{5}$ It is worth noting that the morphology of English permits final coronal fricatives for the plural, the possessive and the third-person singular. Some analyses of the English syllable have argued for only a single coda slot (Borowsky 1989, Harris 1994, Hammond 1999). Under these analyses, the final coronal fricatives cannot be syllabified as part of a syllable that already ends in a consonant. Because the morphology requires that these final fricatives be realized, the English speaker is forced to accept that this class of sounds is tolerated outside the syllable, at least in final position. It is not a far jump to explore a similar analysis for initial clusters, as well. Perhaps, then, there is a correlation between the morphology and syllabification in other languages that appear to allow initial strings

\footnotetext{
${ }^{5}$ In addition to the coronal fricatives, the coronal stops [t, d] are also allowed in coda position. There is a question as to which consonants are allowed to be extrasyllabic. In English, the possible extrasyllabic consonants seem to be phonologically constrained, although there may be morphological and historical influences, as well. Future cross-linguistic research should be conducted to determine what similarity and variation exists across languages with respect to extrasyllabic segments.
} 
of consonants. I will show that this seems to be precisely the case in Spokane Salish and Sipakapense Maya.

Another possible problem with both the sonority analysis and the single-slot analysis is that they predict that certain sound combinations should be allowed in a given language, but these sounds are not present in its inventory. For example, the single-slot analysis on its own does not rule out for Chinese any of the consonant-approximant clusters that are allowed in English. While the single-slot analysis does predict all sounds that are not used by a given language, it is a sufficient representation for all of the sounds that are used by a given language. For example, Duanmu (2002) reports that the cluster [tl] is unattested in English. The single-slot analysis predicts that this sequence can be represented as a single segment. ${ }^{6}$ The additional assumption of the sonority analysis that the two sequences of the cluster must be homorganic predicts that [tl] should not be allowed. While it is true that this sequence of sounds is not generally found in American English, some native speakers of American English pronounce the name of the Native American tribe of the Pacific Northwest [tlingit], spelled 'Tlingit'. Even if this is a mispronunciation, American English speakers to not seem to find especial difficulty with [tl] and do not repair it with epenthesis or deletion. Therefore, even if this sequence is rare, it should still be allowed by both analyses. This sequence is predicted not to exist by the additional assumptions of the sonority analysis, which are not maintained by the single-slot analysis. It is sometimes difficult to determine whether a possible cluster is missing in a given inventory because of a historical accident or because it is ungrammatical. The case of the missing [tl] cluster seems to be a case that is rare or nonexistent for historical reasons; it is not genuinely ungrammatical by English phonotactics.

\footnotetext{
${ }^{6}$ Rusty Barrett (p.c.) points out that the sequence [tl] behaves as a single segment in many languages as $\left[\mathrm{t} \int\right]$ does in English.
} 


\section{Spokane Salish}

Bates and Carlson (1992), building on the classic work of Bagemihl (1991) on Bella Coola (part of which is discussed in Section 4), argue that Spokane Salish has a very simple syllable structure, despite the presence of long strings of obstruent consonants, as in (11) and (12). Example (11) shows seven voiceless consonants preceding the single stressed vowel. Example (12) shows three voiceless consonants preceding and four following the stressed vowel.

(11) $s c \mathrm{k}^{\mathrm{w}} \lambda^{3} \mathrm{k}^{\mathrm{w}} \lambda^{\mathrm{u}} \mathrm{stn}$

/s-č-CV-CVC-k ${ }^{\mathrm{w}} \mathrm{i} \lambda$-us-tn/

NOM-on-DIM-PL-come off-eye/face-INSTR

'little eyes'

(12) tštišš ttx ${ }^{\mathrm{W}}$.

/CVC-tiš-lt-ex ${ }^{\mathrm{w} /}$

PL-sweet-BEN-TRANS-2SG

'You sweetened it for them.'

Bates and Carlson (1992) cite data from the Repetitive (REP) as evidence of the simple syllable structure in Spokane. There are two patterns of surface forms that correspond to the repetitive glosses. In one pattern, there appears to be an -e-infix following the initial segment of the root. The schema for this pattern is given in (13), with representative examples given in (14) and (15).

(13) $/ \mathrm{e}+\mathrm{C}_{1} \mathrm{C}_{2} \mathrm{VC} / \rightarrow\left[\mathrm{C}_{1} \mathrm{eC}_{2} \mathrm{VC}\right]$

(14) snpatáx ${ }^{\mathrm{w}} \mathrm{mn}$

/s-n-p-e-táx ${ }^{\mathrm{w}}$-min/ $<\sqrt{ }$ ptax $^{\mathrm{w}}$

/NOM-in-REP-spit-INSTR/ 


\section{'spittoon'}

(15) snq̉espl̉scútmn

/s-n-qu-e-sp-ls-cút-min/ $<\sqrt{ }$ q'sip

/NOM-in-REP-long time ago-feeling-REFL-INSTR/ 'second-hand-store'

In the other pattern, shown schematically in (16), $-e$ - is preceded by a copy of the root-initial consonant. Examples of this type are given in (17) and (18). ${ }^{7}$

(16) $/ \mathrm{e}+\mathrm{C}_{1} \mathrm{VC} / \rightarrow\left[\mathrm{C}_{1} \mathrm{eC} \mathrm{CC}_{1} \mathrm{VC}\right.$

(17) šelntén.

$/$ š-e-l-nt-én/ $<\sqrt{ }$ šil

REP-chop-TRANS-1SG

'I chopped it up repeatedly'

(18) wečmiús

$/$ w-e-č-mtús/ $<\sqrt{ }$ wič

/REP-see-visions/

'having hallucinations'

Bates \& Carlson (1992) analyze these data as crucially providing evidence that the initial segments in roots such as tax $^{w}$ 'spit' are unlicensed (unsyllabified) after an initial syllabification of the word, at which point the REP morpheme, which corresponds to a CVsyllable, is prefixed. The initial unlinked phoneme is then available

\footnotetext{
${ }^{7}$ Examples (14)-(15) and (17)-(18) show that sonorant consonants are glottalized in the repetitive form, and $-e$ - lowers to $-a$ - before uvulars. Also, these examples show that prefixes are outside the domain of the phonological processes that take place on the root. For example, the prefixal morpheme $-n-$, meaning 'in' is not glottalized.
} 
to form the onset of the REP syllable.

This type of cluster simplification is entirely consistent with a simple CVX syllable structure, although it is not clear that reference must be made to a template for the repetitive morpheme, as Bates and Carlson suggest. Rather, the templatic effects can be accounted for through the interaction of various phonological constraints. The location of the apparent infix is conditioned by the requirement that all syllables must have onsets (ONSET). For this reason, the morpheme $-e$ - could never surface in absolute initial position. Given this inviolable constraint in Spokane, the two attested patterns best satisfy the other phonological constraints of the language given the input. In the case where the root only possesses a single onset, the root-initial onset consonant is copied to the onset slot of the syllable with $-e$ - in its nucleus. When there is an underlying cluster in the onset, the cluster is broken up to satisfy ONSET and to avoid the cluster. A copy of the initial consonant of the underlying cluster is not used to fill the onset of the syllable with $-e$ - in its nucleus because a complex cluster would otherwise remain in the output. In this case, a violation of Prosodic Licensing can be avoided. Elsewhere in these words, unsyllabified segments are allowed to surface because of morphological and phonological demands. In some cases, stressless vowels are compelled to delete, even if the resultant string of consonants cannot be fully parsed due to the fact that certain morphological material cannot be deleted. In other cases, as in the repetitive formation, the most parsimonious output avoids unsyllabified outputs.

There is some evidence that deriving the repetitive forms requires reference to a prosodified form to which stress has been applied and other phonological processes such as vowel deletion have already occurred. However, it seems that no reference need be made to the pre-existing syllable structure of the input form. Consider the example from (17). While the root is šil, the input to the final repetitive form crucially lacks the vowel [i] because the 
unattested output $\check{s}$ ešil would be otherwise predicted. Also, it is noteworthy that sonorant consonants are allowed to fill the nucleus position in surface forms, but they must not be syllabic at the point where the repetitive formation applies. If, for example, the lateral were syllabic in the input to (15), which Bates and Carlson claim to be šlntén ${ }^{8}$, the unattested *šešlntén would be predicted.

Interestingly, the repetitive form of CRVC roots indicates that the consonant-resonant string is simplified with $-e$ - between the consonant and the resonant $\mathrm{R}$, as opposed to a logical alternative where an identical copy of the consonant-resonant sequence surfaces before the $-e$ - immediately preceding the initial consonant-resonant sequence in the root. Apparently, just because two sounds can be a single segment does not necessarily imply that all languages treat them as a single sound.

If there are truly no onset clusters in Spokane, the language poses no problems for the CVX theory as far as the representation of all possible clusters as a single segment. Likewise, there would be no problems for an analysis of syllable structure with respect to sonority, either: the sonority scale could be organized for Spokane such that there is only a difference between consonants and vowels, with no subdivisions of the set of consonants, or the sonority scale could be organized just as it is for English or any other language that could be considered the "default" scale, with the MSD being the difference between the highest and lowest segment types on the scale.

\section{Bella Coola}

In a language related to Spokane, Bella Coola, Bagemihl (1991)

\footnotetext{
${ }^{8}$ Without REP formation, Bates and Carlson report that this form can surface with a syllabic [1] to mean 'I chopped it.'
} 
gives evidence that consonant-resonant onsets are, in fact, allowed, providing examples such as (19)-(21).

(19) $x^{w}$ nat $\rightarrow \mathrm{x}^{\mathrm{w}} \mathrm{n}_{1} \mathrm{x}^{\mathrm{w}}$ naak-i 'spring of water-DIMINUTIVE'

(20) skma $\rightarrow$ skmkma-y 'moose-DIMINUTIVE'

(21) stq $^{\mathrm{w}}$ lus $\rightarrow$ stq $^{\mathrm{w}} \mathrm{lq}^{\mathrm{w}}$ lus-i 'black bear snare-DIMINUTIVE'

Bagemihl (1991) points out that obstruent-obstruent and sonorant-sonorant sequences, however, are not permitted in onset position, citing evidence from patterns of reduplication. $\mathrm{He}$ attributes this fact to a restriction that sonority must rise within the onset. If we take Bagemihl's generalization to be true that any obstruent can combine with any sonorant in onset position, but no two obstruents, nor any two sonorants, can combine, we run into the same problem of loss of generality that we had with Chinese in accounting for the data with a sonority analysis, since we would have to construct a sonority scale for Bella Coola that is different from both English and Chinese. The sonority scale for Bella Coola would have to group all obstruents together, ignoring their differences, and all resonants together, ignoring their differences.

The Bella Coola data also pose a problem for the CVX theory. Bagemihl (1991) states that the set of resonants in Bella Coola is: $[\mathrm{m}, \mathrm{n}, 1, \mathrm{y}, \mathrm{w}]$. The obstruent-[1], obstruent-[y] or obstruent-[w] combinations can easily be represented as a single segment under the CVX theory, but it is impossible to represent any obstruent-nasal sequence as a single segment, given their differing values for the feature [nasal] and No Contour Principle.

Cook (1994) argues against Bagemihl's (1991) analysis of reduplication in Bella Coola, providing his own analysis, and he also argues against Bagemihl's claim that there is "moraic licensing" in the language. Instead, to account for the presence of unsyllabified 
obstruents in Bella Coola, Cook (1994) argues that the phonological process of Stray Erasure is absent in the language. Both authors are in agreement that the syllable structure of Bella Coola is of a relatively unmarked kind. However, it remains an issue whether the syllable structure of Bella Coola allows syllabified consonantresonant sequences such as $\left[\mathrm{x}^{\mathrm{w}} \mathrm{n}\right]$ and $[\mathrm{km}]$, which cannot be represented as a single segment, to be syllabified in word-medial position.

It is worth noting that Bella Coola has a number of C-prefixes, which parallels English suffixes. As was suggested above for English and Spokane Salish, morpho-phonological constraints in Bella Coola could presumably force the realization of these segments, even if they cannot fit into a proper syllable. Once wordinitial segments outside the syllable are permitted in the language, morphosyntactic processes such as compounding might be able to derive new lexical items with word-internal sequences that cannot be syllabified. Since prosodic licensing is not a genuine requirement of the CVX theory, the unsyllabified internal sequences are not really a problem for CVX. The question as to the importance of prosodic licensing and stray erasure, however, remains to be addressed.

\section{Sipakapense Maya}

The case of Sipakapense Maya (Barrett 1999, 2000) is similar to Spokane Salish and Bella Coola in that it allows long strings of initial consonants in fully inflected forms, as in (22)-(24).

(22) $\int \operatorname{tkp} \int \mathrm{o} \chi$.

$\int \mathrm{t}-\varnothing-\mathrm{k}-\mathrm{p} \int \mathrm{\alpha} \chi$

FUT-3SABS-3PERG-shatter 
'They are going to shatter it.'

(23) $\int t q s b^{\prime} \chi a \chi$.

$\int \mathrm{t}-\varnothing-\mathrm{q}-\mathrm{sb}^{\prime} \chi \mathrm{a} \chi$

FUT-3SABS-1PERG-whack

'They are going to whack him/her/it.'

(24) tkk'is.

$\mathrm{t}-\varnothing-\mathrm{k}-\mathrm{k}$ ' is

DUB-3SABS-3PERG-finish

'They will (probably) finish it.'

Synchronically monomorphemic roots seem to allow an almost unrestricted set of up to two initial consonants, regardless of sonority or whether the two segments can be represented as a single segment by the No Contour Principle, as shown in (25)-(34).

(25) tkon

(26) k $\chi i b ’$

(27) $\mathrm{knaq}$

(28) tlul

(29) ts'kin

(30) $\chi \mathrm{me}$ ?t

(31) $\operatorname{msurs}$

(32) nmaaq 'blackberry'

'four'

'bean'

'zapote (fruit)'

'bird'

'bark'

'belly button'

'big' 
92 CVX Theory in CCCCCCVX Languages: Implications for Universal Grammar

(33) mlax

'large pile'

(34) wnaq

'person'

There are a few restrictions, however; not all $\mathrm{CC}$ sequences are allowed in Sipakapense. The first segment of the root-initial cluster cannot be a glottal stop or a glide, and the two segments of the cluster cannot be identical, i.e., no geminates are allowed (Barrett 1999, 2000).

Like English, the coronal fricatives $[\mathrm{s}, \mathrm{S}]$ are also tolerated as a third consonant in initial position of a synchronically monomorphemic root, as in (35)-(38). However, these CCC clusters are not acceptable word-internally.
(35) Spleey
'yellow bean'
(36) $\int k l e t$
'tadpole with limbs'
(37) Sklob
'intestines'
(38) sktol
'twisted'

The synchronic grammar of Sipakapense also allows up to two "onset" clusters not only in word-initial but also in word-medial position, as in (39)-(44). While some of these forms are synchronically monomorphemic, historically they can all be traced to the combination of at least two CVC stems or a CVC stem plus affixes. $^{9}$

\footnotetext{
${ }^{9}$ Nearly all Proto-Mayan roots were CVC. However, Sipakapense has lost the vowel in many lexical items, and native speakers cannot "reconstruct" it.
} 
(39) q'ey.sb'al 'compost heap' q'eyis-b'al

(40) b'ul.ts'fik 'to embroider' b'ults'VS-ik

(41) ts'an.ts'q'or 'brain' ts'an-ts'q'or < ts'Vq'or (Proto-Mayan)

(42) nax.tnik 'to be late' na $\chi$-tVnik

(43) tf'ik.pnik 'to jump' t $\mathrm{ik}$-pon-ik
(44) rax.lb'al 'calendar' $<$ rax-il-b'al

Medial clusters are quite regularly derived through the process of unstressed vowel deletion. In general, stress falls on the final syllable of a word, with the exception of a few irregular forms with penultimate stress. Stressless vowels normally delete in roots and postverbal affixes before the stressed vowel, but their deletion is constrained by phonotactic rules, as illustrated by (45)-(48). For example, the resultant string of consonants cannot be identical, i.e., no geminates. Likewise, vowel deletion never results in wordmedial CCCC clusters.
(45) tfoq'b'îl
'raccoon' *t tq'bil
(46) Skaypál 'lightning' * Jkypa?


94 CVX Theory in CCCCCCVX Languages: Implications for Universal Grammar

\begin{tabular}{|c|c|}
\hline $\begin{array}{l}\text { (47) q'a?tsúy } \\
\text { *q'?tsuy }\end{array}$ & 'toadstool' \\
\hline (48) Sq'axlób' & 'friend' \\
\hline
\end{tabular}

While many of the clusters that Barrett $(1999,2000)$ reports can be represented as single segments, a large number of these sequences must be two segments given the No Contour Principle. An analysis of syllable structure in Sipakapense couched in the CVX theory is forced, then, to say that Sipakapense tolerates unlicensed internal segments, or possibly that there is further syllabification among the Cs, as in Berber (Dell \& Elmedlaoui 1985, 1988). The problem this seems to pose for the CVX theory is not the fact that there are unlicensed internal segments, but the CVX theory does not seem equipped on its own to predict that at most one unsyllabified segment can occur word-internally. The word-internal restriction is in contrast with the initial position, where there is essentially no limit to the number of unsyllabified initial segments, except that there are only a finite number of morphemes that can occur initially. CVX only says that there can be one segment in the onset slot.

These data are equally problematic for an analysis that refers to sonority because sonority is completely irrelevant in constraining the attested consonant sequences, and there is nothing inherent in an analysis that refers to sonority that could constrain the number of internal unlicensed segments.

If we posit a CCVX syllable template for Sipakapense with no role played by sonority, there is a natural explanation for the limit on internal segments. The CVX theory requires a further stipulative rule to prevent more than one unlicensed internal segment. 


\section{Implications for Linguistic Universals and Phonological Theory}

\subsection{Sonority}

Both the CVX analysis of English and Chinese and any analysis of Sipakapense call into question the role of sonority in phonological theory. If these were the only languages that phonologists considered as empirical evidence, and if there were more unanimity regarding the importance of which representations can count as a single segment, phonology might have a much different, much reduced place for sonority. However, there are many analyses that depend on sonority to explain phenomena that otherwise might appear random. For example, Davis (1998) and Davis \& Shin (1999) show the importance of syllable contact in analyses of nasalization and lateralization phenomena in Korean. Similarly, Rose (2000) illustrates the role of syllable contact in the positioning of epenthetic vowels in Chaha. While some analyses of sonority phenomena probably can be replaced by analyses in the spirit of Duanmu (2002) making reference to whether adjacent segments can form a single segment, it seems unlikely that sonority can be thrown out altogether, although it remains an empirical question that should be tested. This raises a question as to redundancy in grammar. Should two different mechanisms (sonority and (VX) be included in grammar to account for similar phenomena across languages, even if the different mechanisms seem to provide more elegant analyses in each case? Are their effects entirely overlapping?

Current phonological theory will not be turned upside down by the idea that sonority is not the only (or the best) way to analyze various phenomena, although it is not well equipped to deal with issues of universality. In a constraint-based theory such as Optimality Theory (Prince \& Smolensky 1993), syllable-contact 
constraints and constraints relevant to enforcing sonority relations would simply be low-ranked in languages such as Sipakapense (and English, too, assuming the CVX analysis is correct). (See Baertsch (2002) for a current Optimality-Theoretic approach to syllable structure.) It remains an open question whether a theory that assumes a universal syllable structure such as CVX interacts with sonority. ${ }^{10}$ Assuming that there are constraints on both sonority and syllable structure, it is predicted that the two should interact in some languages. Cases of syllable contact presumably would be a good area to look for and to tease apart these effects.

\subsection{Prosodic Licensing and Stray Erasure}

By positing a universal inviolable syllable structure template, the CVX theory makes prosodic licensing and stray erasure violable constraints, to the extent that they play any role in grammar. In Bella Coola, the assumed importance and universality of stray erasure led Bagemihl (1991) to propose that the "stray" internal segments unaffiliated with any syllable were actually associated with moras, and therefore were not subject to stray erasure. Cook (1994) argued against this approach, however, simply parameterizing stray erasure. How does the CVX theory account for languages with attested stray erasure effects? If prosodic licensing turns out to be required as a principle active in some languages, Duanmu's CVX theory is forced to make prosodic licensing a violable constraint that can be ranked with respect to other constraints. In the cases where its effects are seen (i.e., segments are deleted when they cannot be syllabified),

\footnotetext{
${ }^{10}$ In OT, one way of doing this could be done by placing CVX in GEN. Doing so raises numerous interesting questions regarding syllable well-formedness constraints, which are beyond the scope of the present article. Presumably, syllable well-formedness constraints would no longer be necessary (or included in UG) if only candidates with CVX structure were generated as possible candidates.
} 
prosodic licensing is high-ranked with respect to MAX-IO (i.e., no deletion). In cases where unsyllabified segments remain in the output, prosodic-licensing must be dominated by MAX-IO, preventing segmental deletion. It remains somewhat unclear what the gain is of having universal syllable structure at the cost of other universal principles, unless it simply is the possible case that researchers have been wrong: syllable structure is universal and the other principles like prosodic licensing and stray erasure are not. It also remains an empirical question whether there might be some kind of cross-linguistic meta-ranking or preference for prosodic licensing.

\section{Conclusion}

In this article, I have shown that Spokane Salish, Bella Coola, and Sipakapense Maya-three languages that should pose the most difficulty for a theory of universally simple syllable structure because of their long sequences of initial consonants-in fact support the claim that languages universally have relatively simple syllable structure. It remains unclear, however, whether there is a universal syllable structure template, as proposed by Duanmu (2002), or if these simple syllable structures derive from constraint (re-)ranking, as assumed in work like Baertsch (2002) and Prince \& Smolensky (1993).

Duanmu (2002) makes a strong, interesting claim that onsets in English and Chinese are limited to a single slot. This proposal seems to hold for Spokane Salish, a language that superficially looks to have very complicated onsets. However, the Sipakapense Maya data present a problem for the CVX theory: Sipakapense seems to allow up to, but no more than, two word-medial segments in onset position, supporting an analysis with a two-slot onset position that has no constraints on sonority. The Bella Coola data also seem to support a 
two-slot onset template, although additional constraints are required that permit only obstruent-nasal sequences. These facts suggest that although the leading idea of Duanmu's CVX theory-that all languages have a simple syllable structure-is borne out, some of the technical details of the proposal do not work. In particular, it may be necessary to expand the proposed universal syllable structure template to allow for two onset consonants.

\section{References}

Baertsch, K. 2002. An Optimality Theoretic Approach to Syllable Structure: The Split Margin Hierarchy. Unpublished Ph.D. Dissertation, Bloomington, IN: Indiana University.

Bagemihl, B. 1991. Syllable Structure in Bella Coola. Linguistic Inquiry 22, 589-646.

Barrett, E. 1999. A Grammar of Sipakapense Maya. Unpublished Ph.D. Dissertation, Austin, TX: University of Texas. 2000. Output-output Correspondence Constraints in OT:

Evidence from Sipakapense Maya. Paper Presented at Linguistics Colloquium. Austin, TX: University of Texas.

Bates, D. \& B. Carlson. 1992. Simple Syllables in Spokane. Linguistic Inquiry 23, 653-659.

Borowsky, T. 1989. Structure Preservation and the Syllable Coda in English. Natural Language and Linguistic Theory 7, 145-166.

Clements, G. 1985. The Geometry of Phonological Features. Phonology Yearbook 2, 225-252.

Cook, E.-D. 1994. Against Moraic Licensing in Bella Coola. Linguistic Inquiry 25, 309-326.

Davis, S. 1998. Syllable Contact in Optimality Theory. Journal of Korean Linguistics 23, 181-211.

Davis, S. \& S.-H. Shin. 1999. The Syllable Contact Constraint in Korean: An Optimality-Theoretic Analysis. Journal of East Asian Linguistics 8, 285-312.

Dell, F. \& M. Elmedlaoui. 1985. Syllabic Consonants and Syllabification in Imdlawn Tashlhiyt Berber. Journal of African Languages and Linguistics 7, 105-130. 
Dell, F. \& Mohamed E. 1988. Syllabic Consonants in Berber: Some New Evidence. Journal of African Languages and Linguistics 10, 1-17.

Duanmu, S. 1994. Against Contour Tone Units. Linguistic Inquiry 25, 555608.

2002. Two Theories of Onset Clusters. Journal of Chinese Phonology 11, 97-120.

Halle, M. 1995. Feature Geometry and Feature Spreading. Linguistic Inquiry 26, 1-46.

Hammond, M. 1999. English Phonology. Oxford: Oxford University Press. Harris, J. 1994. English Sound Structure. Oxford: Blackwell.

Itô, J. 1986. Syllable Theory in Prosodic Phonology. New York: Garland Press.

Kenstowicz, M. 1994. Phonology in Generative Grammar. Oxford: Blackwell.

Ladefoged, P. \& M. Halle. 1988. Some Major Features of the International Phonetic Alphabet. Language 64, 577-582.

McCarthy, J. 1988. Feature Geometry and Dependency: A Review. Phonetica 43, 84-108.

Prince, A. \& P. Smolensky. 1993. Optimality Theory: Constraint Interaction in Generative Grammar. New Brunswick, NJ: Rutgers University Center for Cognitive Science.

Roca, I. \& W. Johnson. 1999. A Course in Phonology. Oxford: Blackwell. Sagey, E. 1986. The Representation of Features and Relations in Nonlinear Phonology. Unpublished Ph.D. Dissertation, Cambridge, MA: MIT.

Steriade, D. 1989. Affricates are Stops. Paper Presented at Conference on Features and Underspecification Theories. Cambridge, MA: MIT. 1999. Alternatives to the Syllabic Interpretation of Consonantal Phonotactics. Proceedings of the 1998 Linguistics and Phonetics Conference 205-242. 